Proceedings

\title{
Diversification of Symbolic Systems ${ }^{\dagger}$
}

\author{
José Monserrat Neto \\ Department of Computer Sciences, Universidade Federal de Lavras, Lavras 37200-900, Brazil; \\ secretaria@dcc.ufla.br or jose.monserrat.neto@gmail.com; Tel.: +55-35-988313319 \\ + Conference Theoretical Information Studies (TIS), Berkeley, CA, USA, 2-6 June 2019.
}

Published: 19 June 2020

\begin{abstract}
Based on Deacon's biosemiotic theory, the diversification of symbolic systems in human evolution is examined. They are contrasted with human language, chimps using symbolic lexigrams and hominid symbolic systems, like mate contract. Communication, knowledge and normativity are three roles identified in symbolic systems, examined for the power advantages they provide members through emergent constraints whose sources are associated with language, music, marriage and myth, and math and science. Finally, a hypothetical $2^{\text {nd }}$ symbolic hierarchic transition in human evolution is briefly presented.
\end{abstract}

Keywords: language; evolution; symbolic system; emergent constraint

\section{Introduction}

The diversification of symbolic systems in the human evolution is examined. In Deacon's, theory shown in The Symbolic Species [1], the first Symbolic Systems (SSs) - born around 2 million years ago (mya) - gave rise to the human language. However, did they give rise to other symbolic systems, or just language? Are we a symbolic species or a "languaged" species? To check the hypothesis, the features of the other SSs, their similarities, distinctions and their common roles, are examined in order to identify the types of SS and their possible emergent constraints.

\section{Symbolic System of Chimpanzees' Lexigrams}

The transition from indices to symbols is proven in a simple SS learned by chimps through thousands of trials to discover symbolic references in a small six-lexigram system (two foods, two drinks and two verbs: give and pour). Experiments with chimps attest to their ability to communicate via symbol tokens, though mostly indexically realized. In one experiment, scientists has proven the transition from indexical to symbolic interpretation that involved learning a system of combinatorial exclusion relations between lexigrams (e.g., food is not poured). The logic was difficult because they persisted in "assuming" indexical relations between symbol and result. In being successful, they learn the symbolic distinction between liquid and solid. Conclusions: an iconic and indexical infrastructure is essential for symbolic reference; the simple SS is not imposed, but emerges from a system of iconic and indexical references that are used (un)successfully to get food and drink; to leap from icon/index to symbol, chimps have to drop icon/index, to "ignore" the icon/index relationships and perceive what is "behind" them; that is, they have to transcend the icon/index relationships, much as when trying to "read between the lines", one has to transcend literal meaning [2]. Once chimps had learned, it became easier to add other lexigrams, as they only needed to find out whether the new lexigram refers to a new food or drink. If chimps are able to learn such simple SS, so should earlier hominids like homo habilis. 


\section{First Symbolic System of Earlier Hominids}

The social niche of hominids was special. The use of stone tools by upright hominids probably induced the processes of relaxing natural selection pressures at around 2 mya, which led to a reduction in masticatory adaptations and sexual dimorphism, with less intense male-male sexual competition, and a change to a more cooperative social life. However, the social niche of the hunting hominids was unstable. Among all cases of hunting species, the hominid was the only one where there was no alpha hunter who mates with all females. Deacon hypothesizes that the first SS could have been the "mate contract". Through collective rituals, the earlier hominids started to symbolically communicate and regulate who could mate with whom, reinforcing a monogamous life, at least for some time. In Deacon's theory, however, there is no need for the first SS to have been the "mate contract", only that the first SSs should have been as simple as possible and addressed towards solving a hominid problem that could not be sorted out only by symbolic means.

Whatever the first SSs were, they could be under the influence of selection and could have gradually enhanced the symbolic adaptation and transformed into our current language. Therefore, we can imagine other simple SSs; for instance, to communicate kinship or group identity, or an SS of incest taboo, which regulates acceptable mate possibilities and avoids interbreed between close relatives. These SSs are somehow related and may have been born in parallel or together. Another hypothesis is the stone tool itself, which hominids built and used 2 mya. We can think of the stone tool could be a symbol of the members of a hunting group, for instance, symbolically communicating their identity to the group.

\section{Other Symbolic Systems}

After 2 million years, the first SSs transformed into language, art, music, myth, math, religion, science, etc. The key question is: are the later SSs variations on, or distinct from, language? If they are distinct, what are the main differences between them? Are there common features to all SSs? What are the main roles of SSs?

Language is the most sophisticate SS, unique to humans and their most well-marked feature. However, is it the only SS humans have? To check this, some similarities and differences between them are examined.

From Deacon's theory [2], an SS is structured in nested hierarchical levels of semiotic processiconic, indexical and symbolic references. A definition of SS is "a structured and systematic network of symbolic references, reciprocally referenced, that emerges from a previous process of experiencing iconic and indexical references", that is, it emerges in a process of repeated training, ritualistic ceremonies and/or learning. Generally, SSs do not emerge consciously, and the acquiring and use of a symbol system must both be explained.

\section{Three Roles of Symbolic System}

SSs seem to include at least three roles: communication, knowledge and normativity. That is, they communicate a message, give knowledge and regulate a norm. For instance, the symbols of "mate contract" communicate who is "married" with whom, offer knowledge of that situation, and are normative since they regulate who can mate with whom (convention). Is that true for other SSs?

The SS of six lexigrams is, at once, a means of communication to "ask for" a food or drink; knowledge of how to get food and drink; and provides a norm of getting them in the right way (e.g., food is given, drink is poured). The SS of incest taboo, in turn, informs who can mate with whom, represents knowledge of mate possibilities, and is normative about the right and wrong ways that members of different social groups can mate.

Language is the most sophisticated SS, specialized to communicate messages by talking, composed of symbolic words that form sentences which are able to represent anything. It has complex grammar and syntactic rules, and a vast network of words whose meanings are reciprocally defined. From the first SSs, language and the brain co-evolved in a new symbolic niche in such a way to prompt easy learning by children [1]. 
Although language seems to be specific to symbolic communication, patently it gives knowledge about everything in the world, including the here-supposed other SSs. Language seems to be part of other SSs. Perhaps there are no other SSs, just language which is used throughout society. Is that so? The normative role of language is not so clear. Is that a norm of the language, or a norm about something in the world? Is the normative feature about how to mate, or how to get food or drink about language? Or is it about how to communicate rightly, so that the listener can understand without ambiguity? It does seem there is a distinction between the external normative role of language when used to describe the world, and the internal normative role of language to communicate properly. If correct, then other SSs may be distinct from language, although may still be "languaged".

In turn, aesthetic and musical expressions are diverse; they communicate feelings and share emotions, express an internal knowledge about world and people, and may be visual, corporal or musical. Generally, they are not spoken except in singing, theater and poems.

Mathematics and sciences inform a "message" about the world and people, that is also knowledge about them, and express a normative way of how the world is, how it works and how to manipulate it in the right ways, for instance, to make proper tools and get food. The SSs of math and science are somehow "languaged", but are they language? Are their symbols, concepts and theories linguistic? Knowledge about the world is inherently normative, expressing the way things work and defining how they can be manipulated and transformed in useful ways.

If myth is an SS, it is a problematic one, because ancient myths were always spoken orally. Roughly, all myths tell the story of a people, their origin and identity, the origin of their world and all its meanings. They communicate the ideas that are seen as valid in a given society and its culture. Myths also present the current knowledge and set up the normativity of a society, and the morality of what is right and wrong. Is myth a linguistic SS? It does look like myth is a "languaged" SS, but myth extrapolates language; it is not only language. Religion appears later, with the first civilizations. Religion and myth share many common features.

To sum up, the SSs do seem to have at least three roles: communication, knowledge and normativity. Other aspects are not yet clear. SSs seem to constrain human activities, but how exactly? How should we relate SSs with human activities? The normative role of an SS also seems to give symbolic power to certain members of a social group, or to specific roles in social relations: a king, for instance, or the money of our economy. How should SSs be related to the power normativity in social relations?

Some SSs seem to communicate an emotional knowledge linked to personal identity. Such knowledge seems to be somehow related to personal desires. If the normativity of SSs indeed started very early in human evolution, there must have been an evolution of the symbolic ways to represent desire, guilt and self-repression. How can one relate SSs with them? The issues are not raised here to offer answers, just to call attention to the complexity of SSs in human evolution.

\section{Distinct Sources of Emergent Constraints of Symbolic Systems}

A criterion to distinguish SSs is to check whether there is a distinct type of symbol tokens. The SSs of six lexigrams, language, music and math do have specific symbols, tokens of a type. The lexigrams system has six tokens and a very simple logic to get foods and drinks. Language has spoken words, a large vocabulary and proper grammatical logic. Music has its own song tokens, specific "vocabulary" and a rhythmic sound logic. Math also has a specific quantity and operational tokens with its own "grammar" and logic. However, the other SSs do not seem to have their own symbol tokens of a distinct type, actually they are somehow "languaged".

Therefore, two more criteria are raised: one is related to the telos of a SS (the end of people using a SS); and the other to a distinct knowledge and normativity used by people in a specific human activity. The idea is that the sources of emerging semiotic constraints can be distinguished in accordance with the type of SS and its specific telos. In other words, the SSs may emerge by different sources of emergent constraints with distinct ends. 
For instance, the end of language is communication. Its constraints emerge to avoid ambiguities. In turn, the source of the emergent constraints of music is to avoid dissonance of sounds, and math misinterpreting quantities and arithmetic operations. Similarly, for science, it is to avoid misinterpreting the workings of nature, the objectivity of the world. However, in social SSs like myth, things are not so clear. Their source seems to be to avoid social conflicts, or at least to regulate them. If this is correct, then we could think of such a source as the emergent constraints of morality. We still need to deepen the investigation.

The methodological guidelines to deepen the research are both to compare the nested semiotic structures of language with other SSs, and to explore Deacon's pattern of the underlying process of hierarchic transition in evolution [3], trying to apply it to the symbolic level of human evolution.

\section{Idea of a 2nd Symbolic Hierarchic Transition in Human Evolution}

The 1st transition is that from early hominids to humans before the great civilizations, that is, from the first SSs to present language and other SSs. In turn, the hypothetical 2nd transition is from humans of hunting-gathering people to contemporary society. It is an attempt to use the underlying process of hierarchic transition in the symbolic human level [3].

The steps of the 2nd transition are: (1) duplication of forms of getting food; (2) born of 1st sedentary civilizations; (3) relaxed selection effects: longer time to many other human activities; (4) degradation of old social activities like hunting-gathering causing "social addiction", and old SSs (myths) giving rise to religion; (5) duplication of language with the creation of written records; (6) new relaxed selection effects: longer time to think reflexively about knowledge; (7) 1st manifestation of a new synergistic symbolic level with the birth of philosophy and democracy; (8) further duplications, relaxed selection and degradation of knowledge, giving rise to new synergies such as science and technology.

In this speculative scenery, my suspicion is that consciousness plays a key role in the birth of later, complex SSs like philosophy and science. If this is right, consciousness itself must be seen as a semiotic process, nested in some way or another in previous semiotic infrastructures.

\section{Conclusions}

Some SSs are distinct from language, like math, music and art. However, others are not clearly distinguished, mostly social SSs like myth, politics and religion. They seem to be distinct, but are established and used through language. The issue is open. As for the question as to whether we are a symbolic or languaged species, from the current research it seems that we are both. Our unique symbolic competence means that we are able to create SSs other than language, like art, music and math. Even so, they are still realized somehow by language. This means that it is still too early for final conclusions. We need to further investigate and deepen the research.

\section{References}

1. Deacon, T. The Symbolic Species - The Co-Evolution of Language and The Brain; W. W. Norton \& Company: New York, NY, USA, 1997.

2. Deacon, T. The Symbol Concept. In The Oxford Handbook of Language Evolution; Tallerman, M., Gibson, K., Eds.; Oxford University Press: Oxford, UK, 2011; pp. 393-405.

3. Deacon, T. Process Underlying the Hierarchic Transition in Evolution. Unpublished work, 2018.

(C) 2020 by the authors. Licensee MDPI, Basel, Switzerland. This article is an open access article distributed under the terms and conditions of the Creative Commons Attribution (CC BY) license (http://creativecommons.org/licenses/by/4.0/). 